\title{
THE
}

\section{Predation on Prerecruits Can Delay Rebuilding of Depleted Cod Stocks}

Jeremy Collie

University of Rhode Island, jcollie@uri.edu

Cóilín Minto

Boris Worm

Richard Bell

University of Rhode Island

Follow this and additional works at: https://digitalcommons.uri.edu/gsofacpubs

Terms of Use

All rights reserved under copyright.

\section{Citation/Publisher Attribution}

Collie, J., Minto, C., Worm, B., \& Bell, R. (2013). Predation on Prerecruits Can Delay Rebuilding of Depleted Cod Stocks. Bulletin of Marine Science, 89(1), 107-122. doi: 10.5343/bms.2011.1134

Available at: https://doi.org/10.5343/bms.2011.1134

This Article is brought to you for free and open access by the Graduate School of Oceanography at DigitalCommons@URI. It has been accepted for inclusion in Graduate School of Oceanography Faculty Publications by an authorized administrator of DigitalCommons@URI. For more information, please contact digitalcommons-group@uri.edu. 


\title{
PREDATION ON PRERECRUITS CAN DELAY REBUILDING OF DEPLETED COD STOCKS
}

\author{
Jeremy Collie, Cóilín Minto, Boris Worm, and Richard Bell
}

\begin{abstract}
Predation by clupeoid species (e.g., Atlantic herring, Clupea harengus Linnaeus, 1758) on the early life stages of gadoids is hypothesized to be an important source of mortality, especially for Atlantic cod, Gadus morhua Linnaeus, 1758. Adult cod also prey on herring, creating a positive feedback process ("trophic triangle") that may result in alternative dominance patterns of cod or herring depending on the relative levels of mortality. We estimated the effect of herring on cod recruitment with a predator-dependent Ricker stock-recruitment function, fit to time-series data. In this formulation, herring gradually reduce the per capita recruitment rate of cod, but this predation does not result in depensatory dynamics. We incorporated this predator-dependent recruitment function into a multispecies length-based model (LeMans) of Georges Bank, northeast US shelf, to investigate the consequences of predation mortality for the recovery of cod from overfishing. In LeMans, all fished species undergo the same size-dependent fishing mortality, following a logistic selection curve. We investigated two fishing patterns: a selective $\left(L_{50}=65 \mathrm{~cm}\right)$ and an unselective fishery $\left(L_{50}=15 \mathrm{~cm}\right)$. The effect of predation on prerecruits was more pronounced under selective fishing because herring were spared as a result of their small size. In rebuilding scenarios with selective fishing, cod started at low abundance and herring at high abundance. Without fishing, cod could rebuild in 10 yrs even with predation mortality before recruitment. In contrast, with low levels of fishing mortality, rebuilding took 25 yrs and even longer with such predation. These results suggest that predation on prerecruits and fishing can combine to delay rebuilding of depleted cod stocks.
\end{abstract}

Predation is one of the main causes of mortality of fish before recruitment, and it varies over time with the abundance of predator and alternate prey species (Houde 1987, Bax 1998). As such, predation on prerecruits may be an important determinant of recruitment (Sissenwine 1984). Evidence for the importance of predation comes from stomach-content analysis and the estimation of predation mortality rates with multispecies models such as Multispecies Virtual Population Analysis (Sparre 1991, Tsou and Collie 2001). The incorporation of predation into stock-recruitment relationships (Walters et al. 1986) can help to elucidate recruitment dynamics and makes possible prediction of the wider consequences of fishing for both predator and prey population dynamics.

Quantifying predation on fish eggs and larvae is more difficult than that on juvenile fish because most eggs and larvae are rapidly digested and are difficult to detect in predator stomachs. This difficulty has been addressed by means of genetic techniques, which have been used to detect the frequency of occurrence of eggs and larvae in predator stomachs (Rosel and Kocher 2002). Despite the challenges, several studies have suggested that predation on eggs and larva of gadids is a substantial source of mortality (Dann et al. 1985, Segers et al. 2007). These cases include predation by sprat, Sprattus sprattus Linnaeus, 1758, and herring, Clupea harengus 
Linnaeus, 1758, on cod, Gadus morhua Linnaeus, 1758, in the Baltic Sea (Köster and Möllmann 2000), predation by mackerel, Scomber scombrus Linnaeus, 1758, on cod in the Gulf of St. Lawrence (Swain and Sinclair 2000), and predation by herring on cod in the northwest Atlantic (Bakun et al. 2009).

Cod that survive predation become the predators of clupeoids, leading to what is variously known as "predator-prey reversal" (Barkai and McQuaid 1988), "trophic triangles," "cultivation depensation" (Walters and Kitchell 2001), or "predator-prey loop" (Bakun and Weeks 2006). Depending on the feeding dynamics and nonlinear functional responses, this predator-prey reversal can lead to alternative states that are dominated by either gadoids or clupeoids. Though field evidence for this predator-prey reversal is scarce, if present, this mechanism could delay the rebuilding of several depleted cod stocks in the North Atlantic. The effect of Atlantic herring on Atlantic cod recruitment has been estimated empirically with mixed-effects models fit to stock-assessment time-series data (Minto and Worm 2012), in which case the negative effect of herring on cod recruitment is interpreted as predation on cod eggs and larvae. Understanding the detailed population consequences of this process requires that cod and herring be embedded in a community model that accounts for predation by adult cod on herring as a function of the abundances of cod, herring, and alternative prey species.

For example, Speirs et al. (2010) developed a length-structured model of cod and eight interacting species in the North Sea, in which the dynamics of each species was defined by 25 life-history parameters. Predation was determined by a size-preference function combined with species-preference coefficients based on spatial overlap and feeding behavior. Herring were assumed to have a high preference for the eggs and larvae of cod and Norway pout, Trisopterus esmarkii Nilsson, 1855; as a result, predation by herring had a strong effect on cod and Norway pout biomass. High levels of such predation reduced the equilibrium yield of cod, potentially preventing the North Sea cod stock from rebuilding (Speirs et al. 2010).

In the study reported here, we investigated the effect of predation by herring on the early life stages of cod in the Georges Bank ecosystem. We estimated the effect of herring on cod recruitment with a predator-dependent Ricker stock-recruitment function, fit to time series of abundance. This function was incorporated into a multispecies length-based model (LeMans), parameterized for the Georges Bank fish community (Hall et al. 2006). The resulting model was used to investigate the effect of herring predation on the ability of a depleted cod stock to rebuild under different levels of fishing intensity and selectivity.

\section{Methods}

The first component of the model is a predator-dependent stock-recruitment model for cod. Assuming Ricker dynamics in the absence of predation other than cannibalism and a linear predation mortality rate in predator abundance, we formulated the change in abundance of cod prerecruits $N$ by

$$
\frac{d N}{d t}=-\left(q+p S_{0}+a P_{0}\right) N
$$

where $q, p$, and $a$ are the instantaneous density-independent, density-dependent, and predation mortality rates, respectively; $S_{0}$ the initial spawner abundance; and $P_{0}$ the predator 
abundance at time of spawning. Solving Equation 1 with respect to time and setting $t=\tau$ (the age at recruitment), we write

$$
R=\alpha S_{0} e^{-\left(\beta S_{0}+\gamma P_{0}\right)}
$$

where $R$ is recruitment ( $N$ at time $t$ ), $\alpha=\mathrm{e}^{-q \tau} f$ (where $f$ here is fecundity and $N_{0}=S_{0} f$ ), $\beta=p \tau$, and $\gamma=a \tau$. Note that all mortality rates integrate across the time to recruitment. Yearly estimates of cod recruitment and lagged cod spawning-stock biomass (SSB) for Georges Bank and herring biomass from the Gulf of Maine-Georges Bank complex were obtained from stockassessment reports (Overholtz et al. 2004, NEFSC 2008). Equation 2 was fit to these data by maximum-likelihood methods with a gamma error structure.

The predator-dependent stock-recruitment model was incorporated into a length-based multispecies model (LeMans), which was originally parameterized for the Georges Bank fish community by Hall et al. (2006). LeMans tracks the abundance of 21 fish species through 10$\mathrm{cm}$ size classes, and the dynamics of each species are determined by six life-history parameters. Growth is modeled with the von Bertalanffy equation. Ration and growth are assumed to be time invariant, such that growth rates are not food dependent. Residual (nonpredation) natural mortality is a U-shaped function of length. Predation mortality on recruited fish is determined by a log-normal size-preference function combined with a diet matrix that specifies, with $1 \mathrm{~s}$ and $0 \mathrm{~s}$, which predators eat which prey species. Each species is identified as fished or unfished; the fishing mortality on fished species is a logistic function of length. Maturity is likewise specified with a separate logistic function of length for each species. Recruitment of individuals into the smallest size class is specified with a Ricker stock-recruitment function in which the productivity $(\alpha)$ scales inversely with asymptotic length and the density-dependent parameter $(\beta)$ scales inversely with the relative abundance of each species in trawl-survey data (Hall et al. 2006).

In a more recent application of LeMans to the Georges Bank and North Sea fish communities, Rochet et al. (2011) added a size-structured forage species to represent food in the diet of predators other than the modeled fish species. Their Georges Bank key run was used as the basis for our modeling exercise. The recruitment function for cod was modified to incorporate predation by herring on prerecruits with Equation 2, where $R$ is the number of cod recruits into the smallest length class.

For simplicity, all fished species were assumed to be fished with the same size selectivity, so fishing mortality at length $F_{L}$ is

$$
F_{L}=\frac{F_{f}}{1+e^{-\eta(L-L 50)}}
$$

in which $F_{f}$ is the fishing mortality rate on fully recruited sizes, $\eta$ the steepness, and $L_{50}$ the length at 50\% selection. Following Rochet et al. (2011), we used a single value of $\eta=0.25$ to give a relatively steep selection curve and two values of $L_{50}$. With $L_{50}=15 \mathrm{~cm}$, all sizes are fished, including herring (Fig. 1). In contrast, with $L_{50}=65 \mathrm{~cm}$, only the largest individuals, including cod, are fished, and herring are unfished. We refer to these two fishing patterns as size-selective $\left(L_{50}=65\right)$ and unselective $\left(L_{50}=15\right)$. The size-selection curve thus provides a convenient way of contrasting fishing mortality rates of herring and cod, without the need to specify separate fishing mortality rates for each species in the community.

Starting with equilibrium abundances from the key run with no fishing, we created a series of fishing-down scenarios by varying $F_{f}$ between 0 and 1 at intervals of 0.1 . LeMans was run for $50 \mathrm{yrs}$, by which time all species had equilibrated to the given intensity and selectivity of fishing. Additional depletion runs, with finer intervals of $F_{f}$, were made to identify the fishing mortality rate that would result in maximum sustainable yield, $F_{m s y}$, for each selectivity pattern. For the rebuilding runs, the community was initialized in a depleted state and allowed to rebuild for 50 yrs with fishing mortality set at either 0 or $F_{m s y}$. In all simulations we were interested in comparing the additional effect of predation by herring on precruits with 


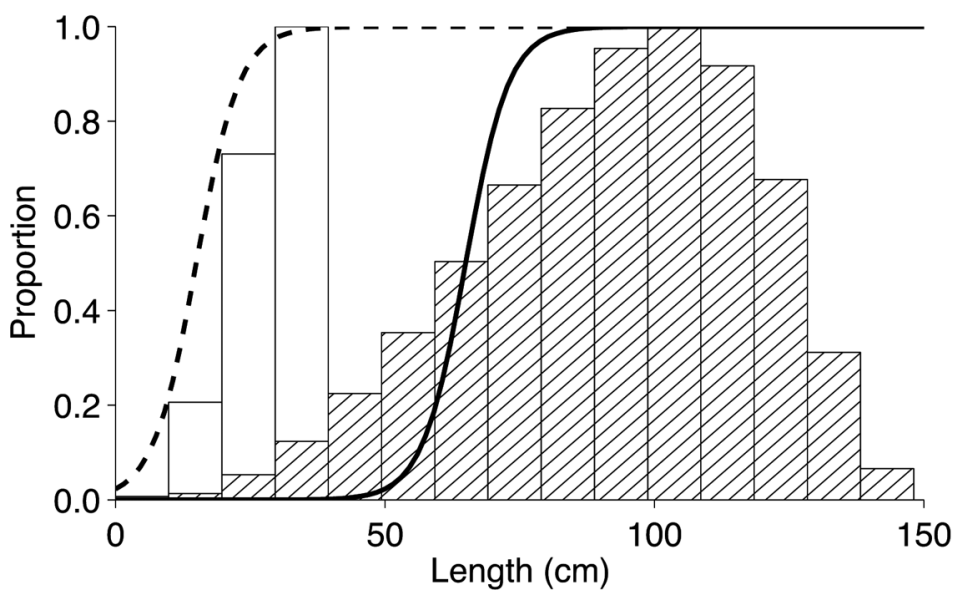

Figure 1. Size selectivity of fishing mortality with $L_{50}=15 \mathrm{~cm}$ (broken line) and $L_{50}=65$ $\mathrm{cm}$ (solid line). For comparison, the normalized distributions of herring (Clupea harengus, hatched bars) and cod (Gadus morhua, open bars) biomass without fishing show which lengths are vulnerable to fishing relative to the two size-selection curves.

the underlying size-based predation within LeMans. Therefore, for each scenario, a pair of simulations was run with the predation coefficient set to either zero (without $\gamma$ ) or its model estimate (with $\gamma$ ). The output measures of interest were cod recruitment $(R)$ and SSB, total herring biomass $(H)$, and predation mortality on herring (M2) summed over size classes.

\section{RESUlts}

The fitted parameters (Table 1) imply a family of cod stock-recruitment curves, one curve for each level of herring biomass (Fig. 2). The effect of predation by herring on cod prerecruits is to decrease the effective productivity $(\alpha)$ without changing the level of SSB at which maximum recruitment occurs $(1 / \beta)$. With this predator-dependent stock-recruitment model embedded in LeMans, equilibrium SSB was reduced by $25 \%$ and recruitment by $29 \%$ (Fig. 2). We therefore expect this mortality to have a significant effect on cod population dynamics.

In the community context, the direct effects of this predation are on herring and cod. In the unfished community, herring was the second most abundant species and cod the fourth (Fig. 3A). If all sizes were fished $\left(L_{50}=15 \mathrm{~cm}\right)$, all fished species became increasingly depleted with increased fishing mortality (Fig. 3B). The three unfished species [sand lance, Ammodytes dubius Reinhardt, 1837; longhorn sculpin,

Table 1. Parameter values $(\alpha, \beta, \gamma)$ of the predator-dependent stock-recruitment function for cod (Eq. 2) estimated by maximum-likelihood methods. Parameter values $\left(\eta, L_{50}\right)$ of the fishing sizeselectivity curve (Eq. 3), which are applied to all fished species. $\mathrm{kt}=$ thousand metric tons.

\begin{tabular}{llcc}
\hline Symbol & Definition & Value & Unit \\
\hline$\alpha$ & Recruits per unit spawning stock biomass & 0.887 & \\
$\beta$ & Density-dependent parameter & 0.013 & $\mathrm{kt}^{-1}$ \\
$\gamma$ & Coefficient of herring predation & $-6.062 \times 10^{-4}$ & $\mathrm{kt}^{-1}$ \\
$\eta$ & Steepness of logistic curve & 0.250 & \\
$L_{50}$ & Length at 50\% selectivity & 15 or 65 & $\mathrm{~cm}$ \\
\hline
\end{tabular}




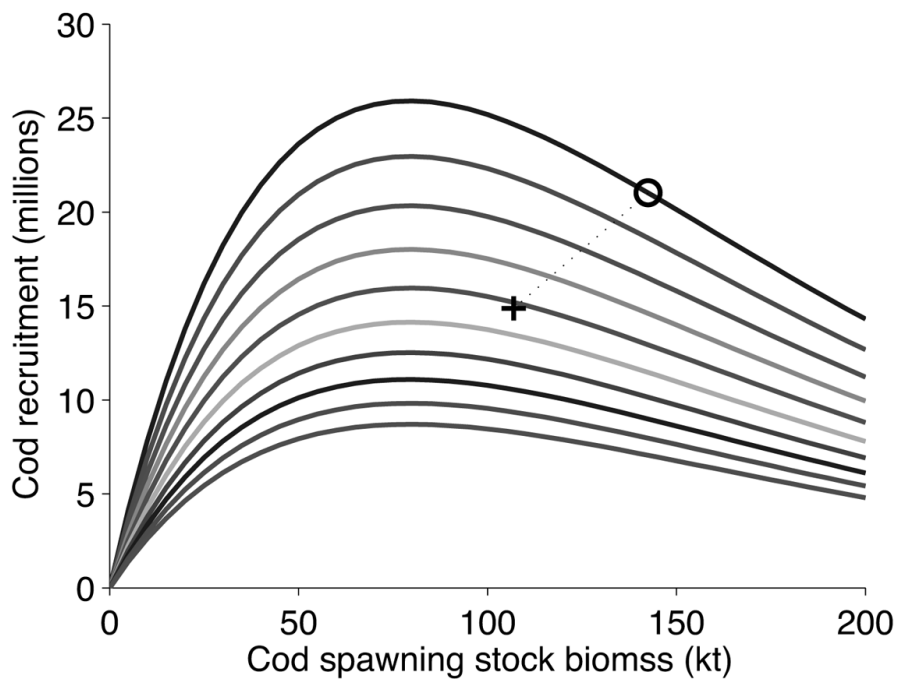

Figure 2. Family of cod (Gadus morhua) stock-recruitment curves described by Equation 2 for values of herring (Clupea harengus) biomass $\left(P_{0}\right)$ increasing from 0 (top curve) to 1800 kilotons (kt; bottom curve). Also shown are the equilibrium values of stock and recruitment with no fishing for the cases without predation on precruits $\left(P_{0}=0\right.$, open circle $)$ and with predation on recruits (plus sign) as calculated with LeMans.
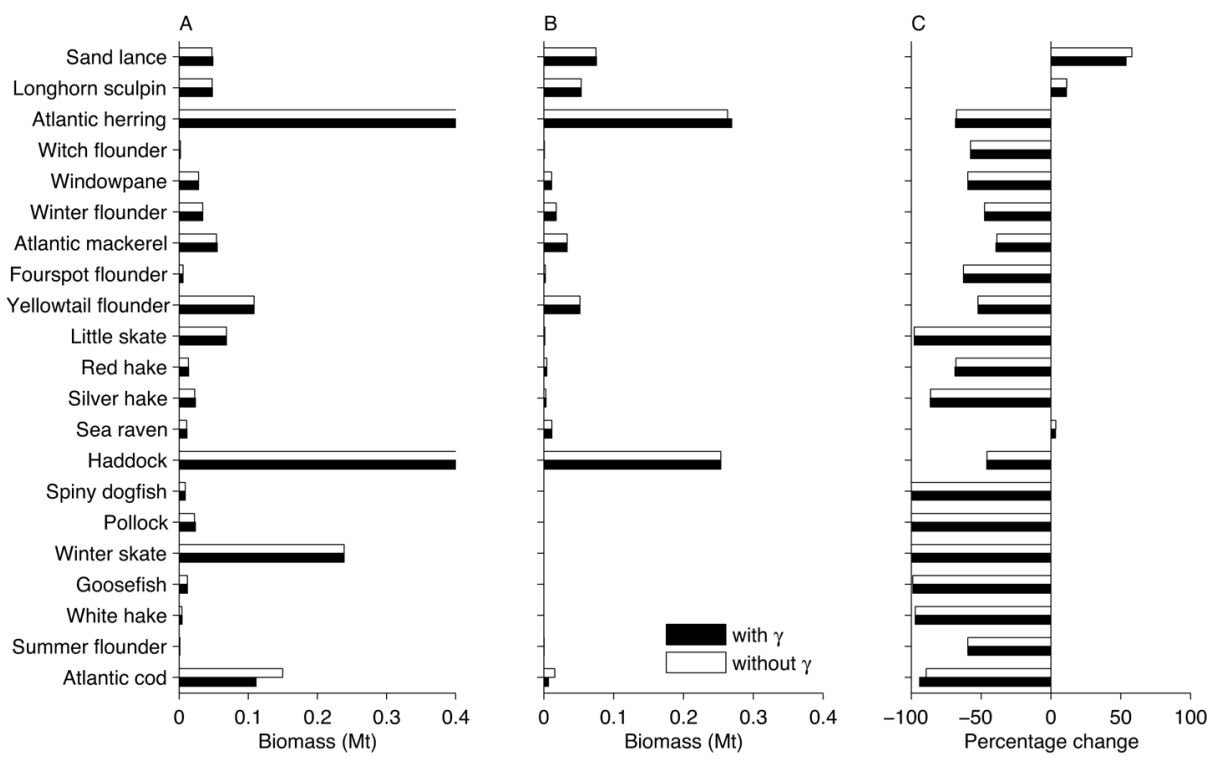

Figure 3. Equilibrium biomass of each modeled species. (A) $F_{f}=0$; the biomass scale is truncated. Biomass values for herring (Clupea harengus) are 0.85 and for haddock (Melanogrammus aeglefinus) 0.47 million metric tons (Mt). (B) $F_{f}=0.4$ with unselective fishing $\left(L_{50}=15 \mathrm{~cm}\right)$. (C) Difference in biomass $(B-A) \times 100 . \gamma$, predation mortality on cod prerecruits. See Appendix 1 for species and authorities. 

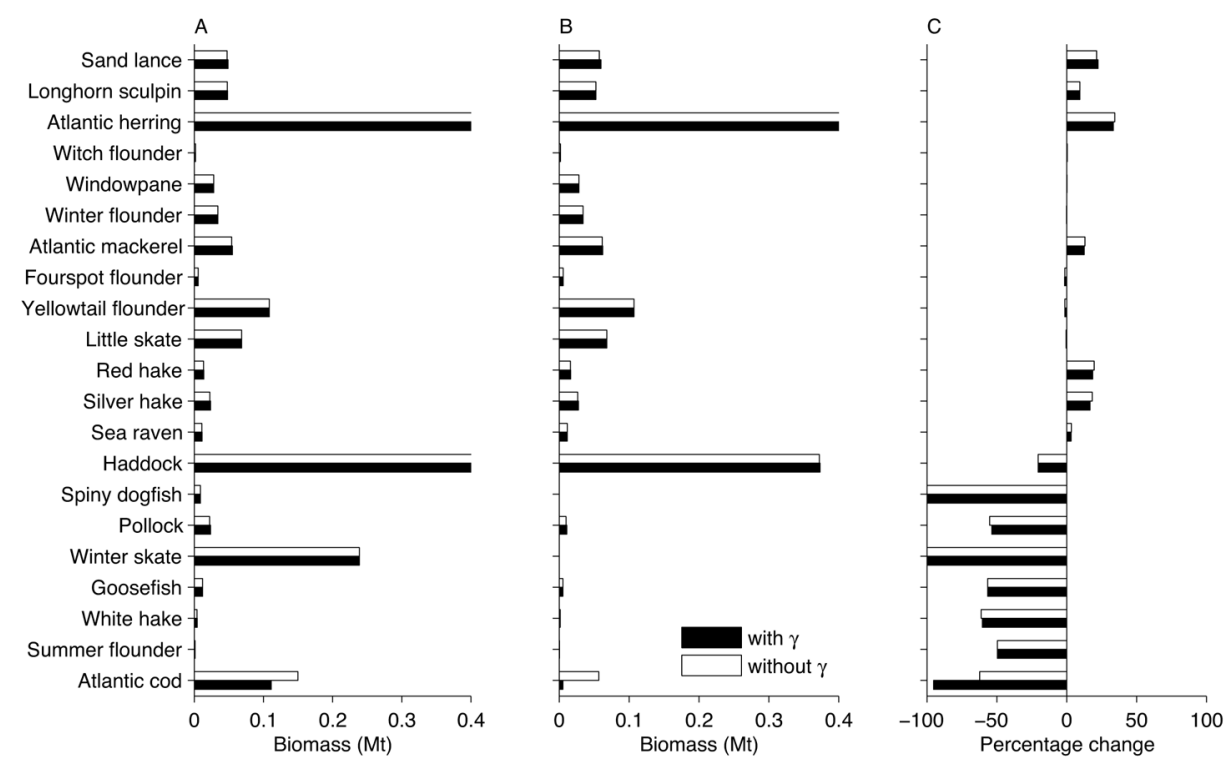

Figure 4. Equilibrium biomass of each modeled species as in Figure 3, but under $F_{f}=1.0$ with size-selective fishing. $\gamma$, predation mortality on cod prerecruits. See Appendix 1 for species and authorities.

Myoxocephalus octodecemspinosus (Mitchill, 1814); and sea raven, Hemitripterus americanus (Gmelin, 1789)] increased in biomass with release from predation, especially sand lance, which is prey to all other species (Fig. 3C). Because herring was fished, the effect of its predation on cod prerecruits was diminished as herring biomass decreased (Fig. 3B).

In contrast, under size-selective fishing, only the larger species, including cod, were depleted as fishing mortality increased (Fig. 4A,B). The small species, including herring, were not fished; several of them increased because of predation release (Fig. 4C). Predation on prerecruits by herring reduced cod biomass, but reduced cod predation had only minor indirect effects on other species, because other predators contributed a large share of the predation mortality on herring. The main drivers of community dynamics in this model community were the direct effects of fishing and the indirect effects of predation on recruited fish. The remaining analyses focused on the dynamics of cod and herring.

Under unselective fishing, the maximum sustainable fishing mortality $\left(F_{f}\right)$ for cod was 0.6 , at which point the SSB was reduced to $0.05 \%$ of the unfished level (Fig. 5). Cod recruitment and SSB were both reduced by predation on precruits. The additional effect of herring predation diminished as fishing mortality increased and herring biomass was reduced, until the maximum sustainable fishing mortality for herring was reached at $F_{f} \sim 0.7$. The fishing mortality rate for maximum cod yield, $F_{m s y}$, was reduced only slightly by addition of $\gamma$ (Table 2). Predation mortality (M2) also declined with increasing $F_{f}$ because the predators were also overfished (Fig. $5 \mathrm{~B}$ ). The decrease in M2 compensated, to some extent, for the increase in fishing mortality. Predation on cod prerecruits slightly decreased M2 and increased herring biomass at low $F_{f}$ (Fig. 5B,D). This effect diminished at higher $F_{f}$ as cod biomass was 

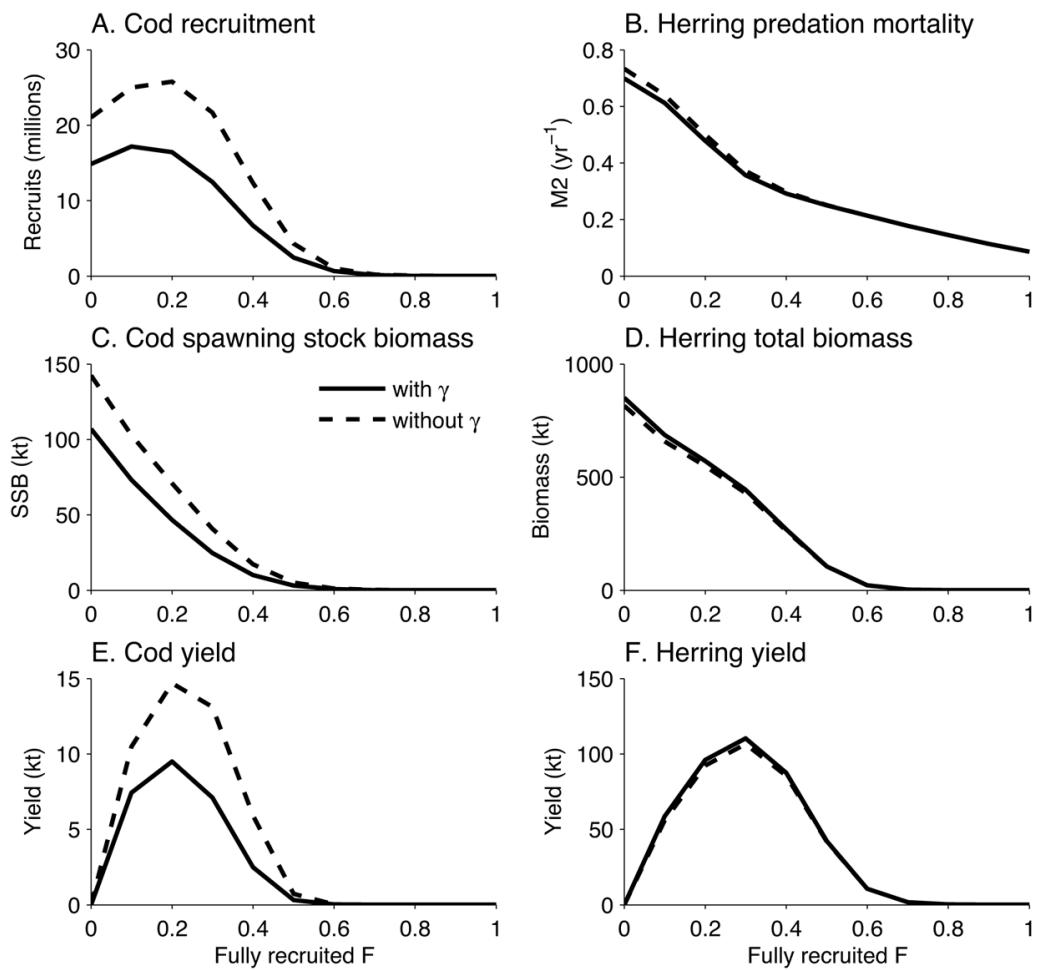

Figure 5. Equilibrium metrics for cod (Gadus morhua) and herring (Clupea harengus) at the end of 50-yr simulations as functions of increasing fishing mortality $\left(F_{f}\right)$ with unselective fishing. SSB, spawning stock biomass; $\gamma$, predation mortality on cod prerecruits.

depleted. Under higher-fishing-mortality regimes $\left(F_{f}>0.4\right)$ the predation mortality on herring was due to other predators, including haddock, Melanogrammus aeglefinus (Linnaeus, 1758), longhorn sculpin, and sea raven (the latter two species were unfished).

Under size-selective fishing, the effective mortality for a given level of fully recruited fishing mortality, $F_{f}$, was much lower. Cod biomass declined with increasing $F_{f}$, but even $F_{f}=1$ was sustainable (Fig. 6). Predation by herring on cod prerecruits had a large effect on cod recruitment and SSB because herring was unfished. The fishing mortality rate for maximum cod yield, $F_{m s y}$, was halved by addition of $\gamma$ (Table 2 ).

Table 2. Reference levels for cod and the corresponding equilibrium abundances of cod and herring under different scenarios of fishing and mortality before recruitment. The reference levels are the fishing mortality rate $\left(F_{m s y}\right)$ for maximum sustainable yield (MSY) and the corresponding spawning stock biomass, $B_{m s y} . \mathrm{kt} \stackrel{m s y}{=}$ thousand metric tons.

\begin{tabular}{llccccc}
\hline Fishery & $\begin{array}{l}\text { Predation on } \\
\text { prerecruits }\end{array}$ & $\operatorname{Cod} F_{m s y}$ & $\begin{array}{c}\text { Cod MSY } \\
(\mathrm{kt})\end{array}$ & $\begin{array}{c}\operatorname{Cod} B_{m s y} \\
(\mathrm{kt})\end{array}$ & $\begin{array}{c}\text { Cod recruitment Herring biomass } \\
(\text { millions })\end{array}$ & \multicolumn{1}{c}{$(\mathrm{kt})$} \\
\hline Unselective & Without & 0.23 & 14.91 & 62.68 & 25.25 & 520 \\
Unselective & With & 0.20 & 9.49 & 46.14 & 16.28 & 571 \\
Selective & Without & 0.66 & 25.84 & 67.34 & 25.59 & 1,063 \\
Selective & With & 0.33 & 11.06 & 47.79 & 13.05 & 960 \\
\hline
\end{tabular}



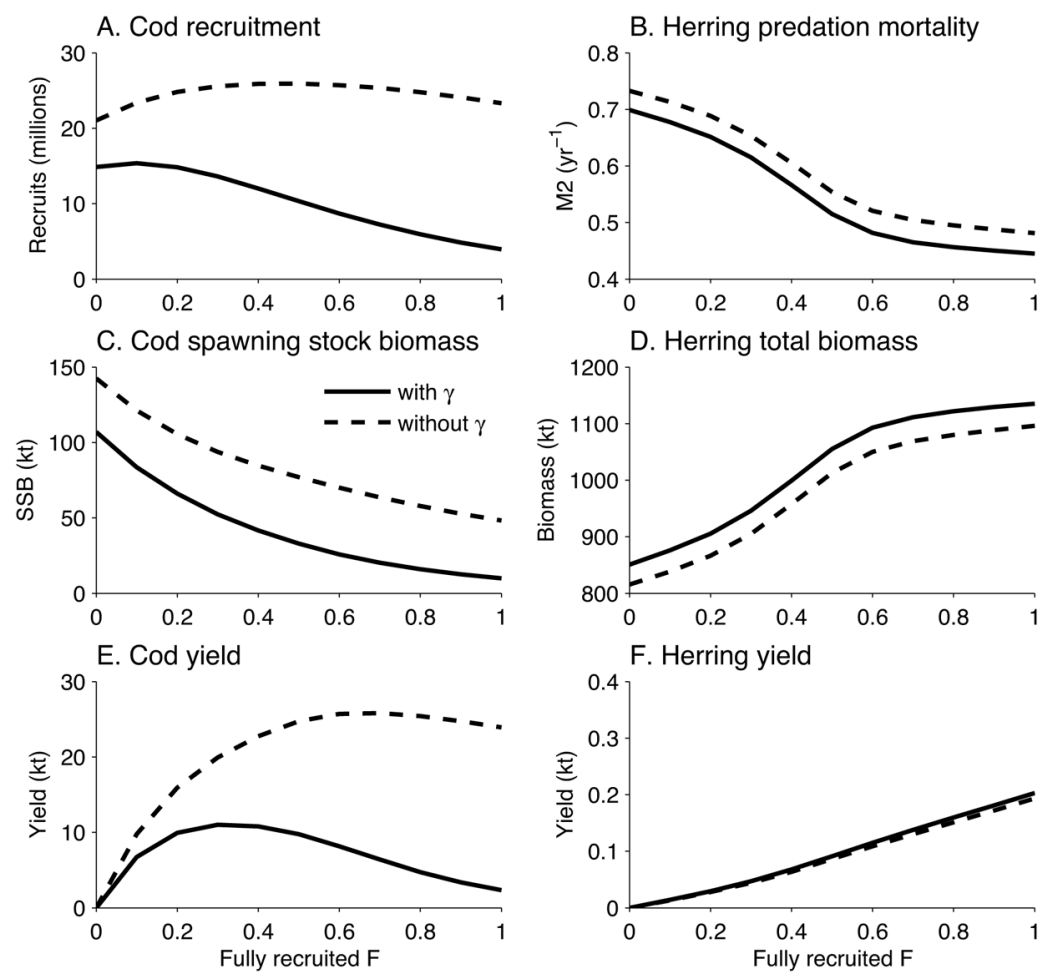

Figure 6. Equilibrium metrics for cod (Gadus morhua) and herring (Clupea harengus) as in Figure 5, but under size-selective fishing. $\gamma$, predation mortality on cod prerecruits.

Herring biomass increased with increasing fishing mortality as predation mortality decreased because of predator release (Fig. 6D). The addition of predation on cod prerecruits increased herring biomass by about $5 \%$ and decreased predation on herring at all levels of fishing mortality (Fig. 6B), but this difference in predation mortality was small compared with the magnitude of $\mathrm{M} 2$, which was due to a number of other predators.

Rebuilding scenarios were initiated with cod depleted to low levels. A fishing mortality rate of 0.4 with unselective fishing gave a level of depletion similar to that with $F_{f}=1$ under size-selective fishing (Figs. 5, 6). With no fishing during rebuilding, the scenarios for the selective and unselective fisheries started with similar levels of cod but different herring biomass (Figs. 7, 8). Cod recruitment and SSB both increased in a cyclic fashion and appeared to be equilibrating after $25 \mathrm{yrs}$; with predation by herring on prerecruits, cod abundance rebuilt to a lower level but still reached the biomass level corresponding with MSY, $B_{m s y}$, within 10 yrs (Figs. 7C, 8C). Herring biomass increased rapidly with no fishing, reaching a maximum at approximately 15 yrs. Predation mortality on herring also increased as the predators recovered, eventually reducing herring biomass.

With unselective fishing mortality during rebuilding $\left(F_{f}=F_{m s}\right)$, cod recruitment and SSB both increased monotonically, reaching equilibrium at about 25 yrs (Fig. 7A,C). Herring biomass also increased monotonically to a lower level, despite 

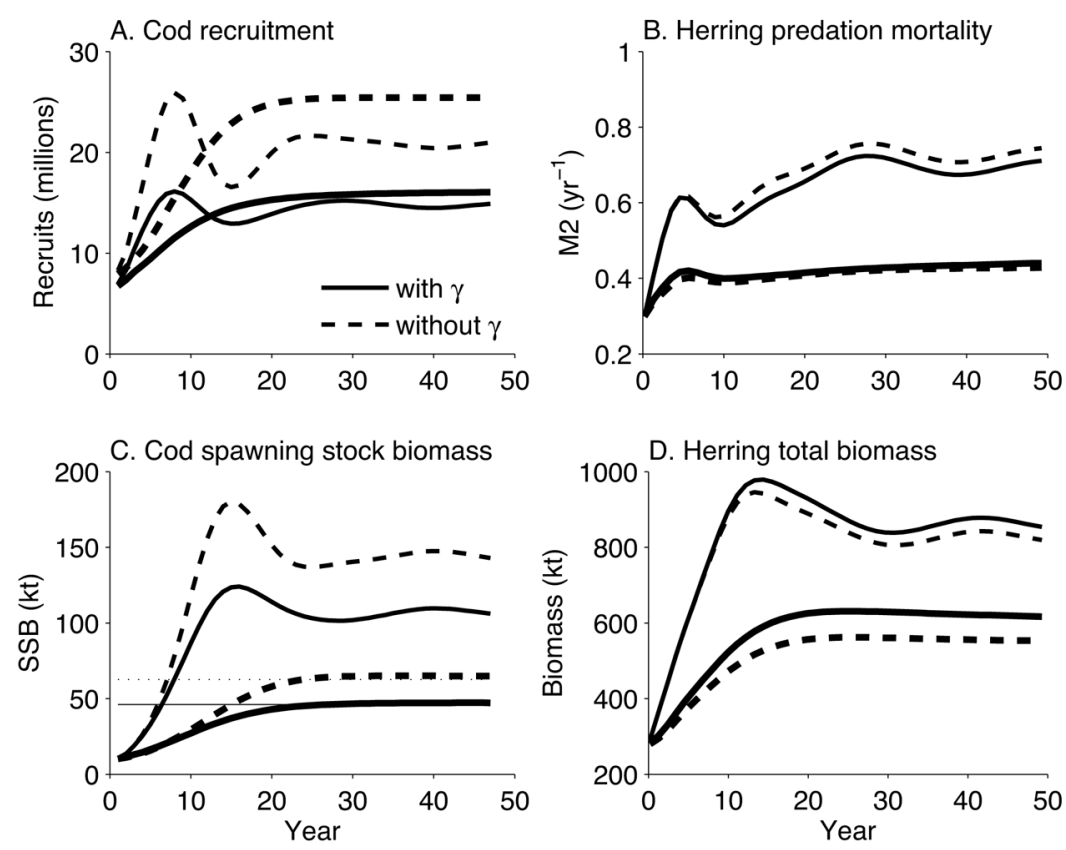

Figure 7. Cod (Gadus morhua) rebuilding scenarios without fishing (thin lines) and with unselective fishing at $F_{m s y}$ (thick lines). Dotted horizontal lines indicate biomass levels corresponding to maximum sustainable yield $\left(B_{m s y}\right) \cdot \gamma$, predation mortality on cod prerecruits.

decreased predation mortality, because herring was also fished (Fig. 7D). The additional effect of predation on prerecruits (with $\gamma$ ) reduced cod abundance as expected, with SSB rebuilding more slowly to a lower equilibrium level (Fig. 7C). Herring biomass was somewhat higher with $\gamma$ (Fig. 7D) because of the lower $F_{m s y}$, but herring predation mortality was almost unaffected.

In rebuilding scenarios after intense size-selective fishing, rebuilding with $F_{f}=$ 0 was similar to that in the unselective scenario, except that herring started from a higher initial biomass (Fig. 8). Otherwise, the dynamics of cod recruitment and SSB were similar. Herring biomass decreased, and predation mortality on herring increased, as predator species recovered from depletion. The additional effect of predation by herring on prerecruits delayed cod rebuilding when herring started at high abundance. With fishing at $F_{f}=F_{m s y}$ during the rebuilding, cod recruitment was reduced (Fig. 8A), and cod SSB rebuilt more slowly to a lower equilibrium level (Fig. 8B). Herring biomass and predation mortality changed only slightly because the predator populations recovered slowly, if at all, under size-selective fishing (Fig. 8B,D). The effect of predation on cod prerecruits was most apparent when cod were subject to a combination of predation and fishing mortality. Both cod recruitment and SSB increased gradually, reaching equilibrium levels after about $35 \mathrm{yrs}$ (Fig. 8A,C). In this scenario, the lower cod biomass had limited effects on herring predation mortality and biomass (Fig. 8B,D). 

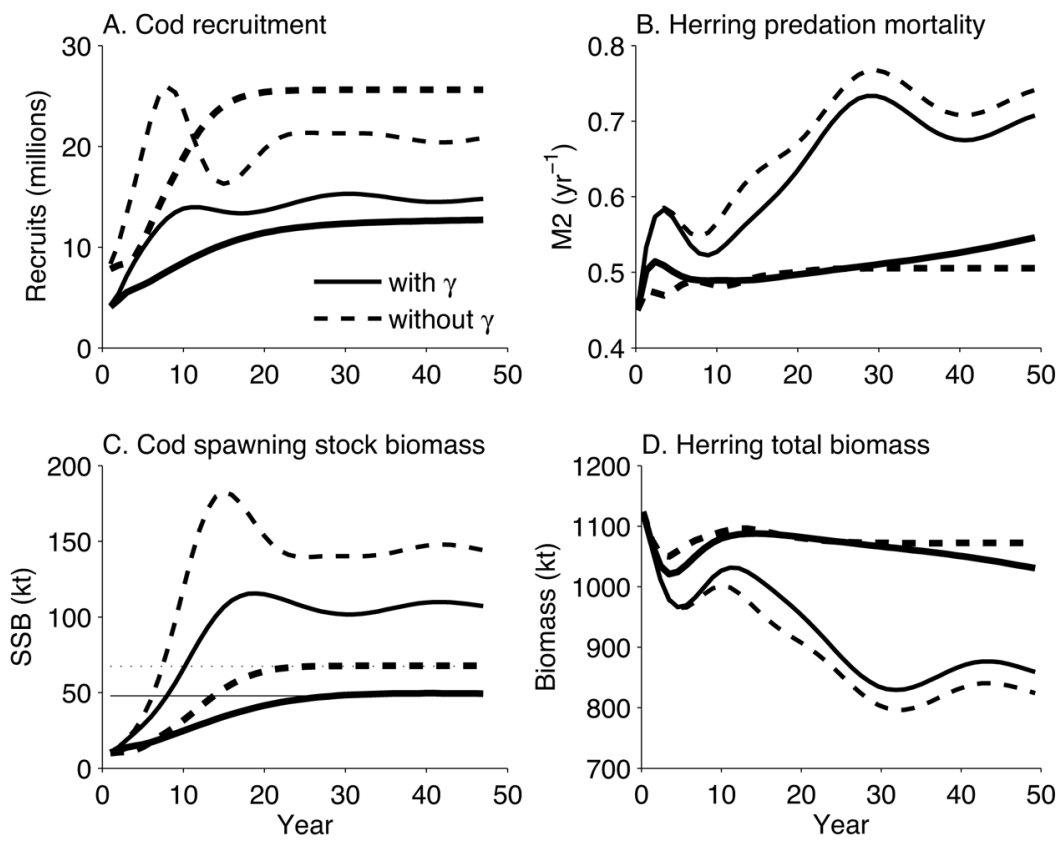

Figure 8. Cod (Gadus morhua) rebuilding scenarios without fishing (thin lines) and with sizeselective fishing at $F_{m s y}$ (thick lines). Dotted horizontal lines indicate biomass levels corresponding to maximum sustainable yield $\left(B_{m s y}\right) \cdot \gamma$, predation mortality on cod prerecruits.

\section{Discussion}

Our modeling study confirmed a potentially large impact of herring on cod recruitment, which could delay rebuilding of depleted stocks. This effect is presumed to result from predation by herring on cod eggs and larvae and represents a significant source of mortality over the life cycle of cod and potentially other groundfish species. A predation triangle exists because larger cod prey on herring, thereby reducing the impact of herring on cod recruitment. Atlantic mackerel may also prey on cod prerecruits (Swain and Sinclair 2000), but this effect was not significant in the Georges Bank community, according to a recent metaanalysis (Minto and Worm in press).

Simulation trials with LeMans indicated that predation on prerecruits had a large effect, which was amplified by size-selective fishing, such that cod were fished but herring remained unfished. The size-selective fishery resembled the situation on Georges Bank, where mesh-size restrictions have made the fishery increasingly selective for larger sizes (Collie and Rochet 2010). Conversely, the unselective fishery scenario was more like the North Sea, where until recently the fishery captured a broad range of sizes. The size-based representation of fishing in LeMans is a convenient way of representing fleets on the basis of their size selectivity, without the need to specify a fishing mortality rate for each species in the community. We recognize that, in reality, separate fleets fish for pelagic species like herring and demersal species like cod. To some extent, the pelagic and demersal fleets are not independent because some by-catch of demersal species occurs in the herring fishery. 
This multispecies model includes positive feedback, whereby predation by herring on cod precruits in turn reduces the predation mortality on herring (the same applies in reverse for cod predation on herring), but in our model this predation triangle did not lead to depensation and alternative cod-and herring-dominated states. The predator-dependent Ricker model (Eq. 1) is compensatory; predation reduces the per capita production of cod, but the stock-recruitment model is not depensatory. The Type-II functional response that is used to calculate predation mortality within LeMans is depensatory at low prey abundance (Sparre 1991), but the direct interactions between cod and herring are dampened by interactions with other species in the community. Cod preys on seven other species in addition to herring, which are consumed according to their size and in proportion to their availability. In particular, a hypothetical forage species, representing prey species that are not otherwise included in the model, contributes a large portion of the diet, even of piscivorous species. Conversely, herring has 12 predator species, some of which are more abundant than cod [e.g., winter skate, Leucoraja ocellata (Mitchill, 1815)]. In addition, seven species prey on cod postrecruits, according to their size. This dampening of predator-prey feedback is a property of LeMans but may also reflect diffuse predator-prey interactions in the real Georges Bank community (Link 2002), and the more general observation that many weak feeding links in a community act to dampen oscillations between consumers and resources (McCann et al. 1998).

Interpretation of our results clearly depends on the extent to which LeMans captures the dynamics of the real Georges Bank community. The length-based model was not statistically fit to abundance data but was tuned and validated to match basic community indices, including total biomass, rank abundance, size spectra, and predation mortality (Rochet et al. 2011). Predation mortality is governed by a binary diet matrix and a size-preference function, such that all prey of a given size are assumed equally suitable. Predation by cod on herring could be higher if cod preferred herring over other prey species of the same size.

Our interpretation also depends on the uncertainty associated with the input parameters (Table 1). Using a Bayesian implementation and a more recent herring assessment (Shepherd et al. 2009), Minto and Worm (2012) estimated a stronger but more diffuse interaction term of $\hat{\gamma}=-1.29 \times 10^{-3}$ with an $86.4 \%$ probability of being negative. A hierarchical implementation, based on 14 regions, estimated $\hat{\gamma}=-4.4 \times$ $10^{-4}$ for Georges Bank with a $95.4 \%$ probability of a negative interaction. Clearly, the interaction term lies on the border of traditional statistical significance levels and must therefore be interpreted with caution. From this distribution of $\gamma$ estimates we effectively chose two scenarios: "with $\gamma$ " is approximately the 50th percentile, and "without $\gamma$ " is roughly the 90th percentile. In future simulations, $\gamma$ could be considered a random variable with corresponding distributions of response variables.

Our results are consistent with those from other studies of the effects of herring predation on cod prerecruits. In a partial ecosystem model of the North Sea, fishing mortality at 2006 levels (0.6-0.7), combined with strong herring recruitment, caused the cod stock to collapse (Speirs et al. 2010). A lower rate of cod fishing mortality was required to compensate for the mortality of prerecruits from herring. A strength of our study is that the predation function for prerecruits was statistically fit to stock and recruitment data (Minto and Worm in press) instead of being inferred from size-preference and spatial overlap. LeMans includes more species, including alternate predators of herring and prey of cod. The North Sea model included other 
prey species of cod but whiting was the only other significant predator of herring (Speirs et al. 2010). LeMans has also been parameterized for 21 species in the North Sea (Rochet et al. 2011). In that application, herring had seven predator species, cod had 12 prey and eight predator species, numbers similar to those in the Georges Bank food web. A negative effect of herring on cod recruitment was also observed in the North Sea (Minto and Worm in press), such that the modeling approach used here could be applied to that fish community as well.

Similar to ours, recent studies indicate that fisheries are the main regulator of cod population dynamics in the Baltic Sea (Cardinale and Svedäng 2011). Earlier work suggested that increased biomass of sprat and herring in the Baltic Sea negatively affected cod through predation on eggs and competition with larvae for zooplankton prey (Köster and Möllman 2000). The dominance of sprat and herring for two decades was interpreted as a regime shift to a "cod-hostile" stable state (Möllman et al. 2008), but recent substantial reductions in fishing mortality of Baltic cod allowed the stock to rebuild rapidly in the absence of any extraordinarily large year classes (Cardinale and Svedäng 2011). With levels of fishing mortality below $F_{m s y}$, the Baltic cod stock is projected to rebuild to $B_{m s y}$ within 10 yrs (Froese and Quaas 2011). Our results for Georges Bank are consistent with those from the Baltic Sea in that the effect of predation on cod prerecruits is secondary to the first-order effect of fishing.

An important conclusion from our research is that predator-prey interactions within the fish community alter the biological reference points used for fisheries management (Collie and Gislason 2001). The reference points based on MSY depend on fishing intensity and selectivity and therefore the abundance of interacting species. In the work reported here, we assumed common selectivity for all species; the MSY levels can therefore be identified in relation to a single measure of fishing intensity. The addition of mortality on cod prerecruits reduced the reference points $\left(F_{m s y}\right.$, MSY, $\left.B_{m s y}\right)$ substantially; these differences were amplified under size-selective fishing for cod and not for herring. With predation on prerecruits, the cod stock rebuilt more slowly and to a lower $B_{m s y}$. The time required for rebuilding to $B_{m s y}$ was only slightly longer with mortality of prerecruits because the stock was rebuilding more slowly to a lower level. Without fishing, the cod stock reached $B_{m s y}$ within 10 yrs; with fishing at the respective $F_{m s y}$ levels, rebuilding took about 25 yrs and longer under a size-selective fishery.

In this application, herring was only captured by the unselective fishery, which also captured the predators of herring. The $F_{m s y}$ for herring was higher than that of cod, ensuring that herring would be sustained at any fishing rate that sustained cod. The main management implication is that efforts to conserve forage species because of their importance as prey species must also recognize their importance as predators of juvenile fish and as competitors of planktivorous marine mammals and birds. This case is an example of one in which size-selective fisheries may actually create adverse changes in ecosystem structure; such effects could be counteracted by "balanced harvesting" (sensu Garcia et al. 2012), which distributes a moderate mortality across a wide range of species and size classes, ideally in proportion to their natural productivity. 
In conclusion, the existence of predator-prey interactions does not fundamentally alter the theory of fishing and the use of biological reference points to guide management decisions. Maintaining stock size at target levels such as $B_{m s y}$ should in most cases prevent the type of critical depensation described by Walters and Kitchell (2001). Indeed, the biomass trajectories of Georges Bank cod and herring can largely be explained by their respective fishing mortality rates. Herring biomass increased in the early 1990s as fishing mortality was reduced below $F_{m s y}$ (Shepherd et al. 2009). The depletion and lack of rebuilding of Georges Bank cod is largely explained by fishing mortality that remained above $F_{m s y}$ during the entire period of the stock assessment (NEFSC 2008), but to rebuild depleted cod stocks, fishing mortality may have to be reduced further in the presence of predation mortality, particularly on the stages before recruitment. Furthermore, expected rebuilding times and the target $B_{m s y}$ levels may have to be conditioned on the abundance of clupeid predators.

\section{ACKNOWLEDGMENTS}

This paper emerged from a distributed Graduate Seminar at the National Center for Ecological Analysis and Synthesis (NCEAS). We thank the Moore Foundation and NCEAS for supporting this seminar. H Gislason, M-J Rochet, and two anonymous reviewers provided valuable comments on the manuscript draft. JC acknowledges NSF award OCE0814592. This work is contribution number 721 of the US GLOBEC program. Funding to CM was provided by the Irish Department of Education, Technological Sector Research Program, Strand III.

\section{Literature Cited}

Bakun A, Babcock EA, Santora C. 2009. Regulating a complex adaptive system via its waspwaist: grappling with ecosystem-based management of the New England herring fishery. ICES J Mar Sci. 66:1768-1775. http://dx.doi.org/10.1093/icesjms/fsp073

Bakun A, Weeks SJ. 2006. Adverse feedback sequences in exploited marine systems: are deliberate interruptive actions warranted? Fish Fish. 7:316-333. http://dx.doi. org/10.1111/j.1467-2979.2006.00229.x

Barkai A, McQuaid C. 1988. Predator-prey role reversal in a marine benthic ecosystem. Science. 242:62-64. PMid:17757631. http://dx.doi.org/10.1126/science.242.4875.62

Bax NJ. 1998. The significance and prediction of predation in marine fisheries. ICES T Mar Sci. 55:997-1030. http://dx.doi.org/10.1006/jmsc.1998.0350

Cardinale M, Svedang H. 2011. The beauty of simplicity in science: Baltic cod stock improves rapidly in a "cod hostile" ecosystem state. Mar Ecol Prog Ser. 425:297-301. http://dx.doi. org/10.3354/meps09098

Collie JS, Gislason H. 2001. Biological reference points for fish stocks in a multispecies context. Can J Fish Aquat Sci. 58:2167-2176. http://dx.doi.org/10.1139/f01-158

Collie JS, Rochet M-J. 2010. Temporal changes in the diversity of shelf-sea fish communities. ICES CM 2010/Q:03.

Daan N, Rijnsdorp AD, Van Overbeeke GR. 1985. Predation by North Sea herring Clupea harengus on eggs of plaice Pleuronectes platessa and cod Gadus morhua. Trans Am Fish Soc. 114:499-506. http://dx.doi.org/10.1577/1548-8659(1985)114<499:PBNSHC>2.0. $\mathrm{CO} ; 2$

Froese R, Quaas M. 2011. Three options for rebuilding the cod stock in the eastern Baltic. Mar Ecol Prog Ser. 434:197-200. http://dx.doi.org/10.3354/meps09247

Garcia SM, Kolding J, Rice J, Rochet M-J, Zhou S, Arimoto T, Beyer JE, Borges L, Bundy A, Dunn D, et al. 2012. Reconsidering the consequences of selective fisheries. Science. 335:1045-1047. PMid:22383833. http://dx.doi.org/10.1126/science.1214594 
Hall SJ, Collie JS, Duplisea DE, Jennings S, Bravington M, Link J. 2006. A length-based multispecies model for evaluating community responses to fishing. Can J Fish Aquat Sci. 63:1344-1359. http://dx.doi.org/10.1139/f06-039

Houde ED. 1987. Fish early life dynamics and recruitment variability. Am Fish Soc Symp. 2:17-29.

Köster FW, Möllmann C. 2000. Trophodynamic control by clupeid predators on recruitment success in Baltic cod? ICES J Mar Sci. 57:310-323. http://dx.doi.org/10.1006/ jmsc. 1999.0528

Link J. 2002. Does food web theory work for marine ecosystems? Mar Ecol Prog Ser. 230:1-9. http://dx.doi.org/10.3354/meps230001

McCann K, Hastings A, Huxel GR. 1998. Weak trophic interactions and the balance of nature. Nature. 395:794-798. http://dx.doi.org/10.1038/27427

Minto C, Worm B. 2012. Interactions between small pelagic fish and young cod across the North Atlantic. Ecology. 93:2139-2154. http://dx.doi.org/10.1890/10-2036.1

Möllmann C, Müller-Karulis B, Kornilovs G, St. John MA. 2008. Effects of climate and overfishing on zooplankton dynamics and ecosystem structure: regime shifts, trophic cascade, and feedback loops in a simple ecosystem. ICES J Mar Sci. 65:302-310. http://dx.doi. org/10.1093/icesjms/fsm197

NEFSC (Northeast Fisheries Science Center). 2008. Assessment of 19 Northeast groundfish stocks through 2007: Report of the 3rd Groundfish Assessment Review Meeting (GARM III). US Dep Commer, NOAA Fisheries. Technical Report, Northeast Fisheries Science Center, Woods Hole, MA.

Overholtz WJ, Jacobson LD, Melvin GD, Cieri M, Power M, Libby D, Clark K. 2004. Stock assessment of the Gulf of Maine-Georges Bank Atlantic herring complex, 2003. Northeast Fisheries Science Center Reference Document 04-06. 290 p.

Rochet M-J, Collie JS, Jennings S, Hall SJ. 2011. Does selective fishing conserve community biodiversity? Predictions from a length-based multispecies model. Can J Fish Aquat Sci. 68:469-486. http://dx.doi.org/10.1139/F10-159

Rosel PE, Kocher TD. 2002. DNA-based identification of larval cod in stomach contents of predatory fishes. J Exp Mar Biol Ecol. 267:75-88. http://dx.doi.org/10.1016/ S0022-0981(01)00359-8

Segers FHID, Dickey-Collas M, Rijnsdorp AD. 2007. Prey selection by North Sea herring (Clupea harengus), with special reference to fish eggs. ICES J Mar Sci. 64:60-68.

Shepherd G, Cieri M, Power M, Overholtz W. 2009. Transboundary Resource Assessment Committee Gulf of Maine/Georges Bank Atlantic herring stock assessment update. TRAC Reference Document-2009/04. Available from: http://www2.mar.dfo-mpo.gc.ca/science/ trac/documents/TRD_2009_04_E.pdf.

Sissenwine MP. 1984. Why do fish populations vary? In: May RM, editor. Exploitation of marine communities. Berlin: Springer-Verlag. p. 59-94. http://dx.doi. org/10.1007/978-3-642-70157-3_3

Speirs DC, Guirey EJ, Gurney WSC, Heath MR. 2010. A length-structured partial ecosystem model for cod in the North Sea. Fish Res. 106:474-494. http://dx.doi.org/10.1016/j. fishres.2010.09.023

Sparre P. 1991. Introduction to multispecies virtual population analysis. ICES Mar Sci Symp. 193:12-21.

Swain D, Sinclair AF. 2000. Pelagic fishes and the cod recruitment dilemma in the northwest Atlantic. Can J Fish Aquat Sci. 57:1321-1325. http://dx.doi.org/10.1139/f00-104

Tsou T-S, Collie JS. 2001. Predation-mediated recruitment in the Georges Bank fish community. ICES J Mar Sci. 58:994-1001. http://dx.doi.org/10.1006/jmsc.2001.1088

Walters CJ, Kitchell J. 2001. Cultivation/depensation effects on juvenile survival and recruitment: implications for the theory of fishing? Can J Fish Aquat Sci. 57:39-50. http://dx.doi. org/10.1139/f00-160 
Walters CJ, Stocker M, Tyler AV, Westrheim SJ. 1986. Interaction between Pacific cod (Gadus macrocephalus) and herring (Clupea harengus pallasi) in the Hecate Strait, British Columbia. Can J Fish Aquat Sci. 43:830-837. http://dx.doi.org/10.1139/f86-102

Date Submitted: 23 November, 2011.

DATE ACCEPTED: 24 May, 2012.

Available Online: 2 November, 2012.

Addresses: (JC, RB) Graduate School of Oceanography, University of Rhode Island, Narragansett, Rhode Island 02882. Email: <jcollie@mail.uri.edu>. (CM) Marine and Freshwater Research Centre, Galway-Mayo Institute of Technology, Dublin Road, Galway, Ireland. Email: <coilin.minto@gmit.ie>. (BW) Biology Department, Dalhousie University, Halifax, NS B3H4J1, Canada.Email: <bworm@dal.ca $>$.

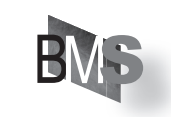


Appendix 1. List of species included in the application of the length-based model (LeMans) to the Georges Bank fish community.

\begin{tabular}{|c|c|}
\hline Scientific name & Common name \\
\hline Ammodytes dubius Reinhardt, 1837 & Northern sandlance \\
\hline Clupea harengus Linnaeus, 1758 & Atlantic herring \\
\hline Gadus morhua Linnaeus, 1758 & Atlantic cod \\
\hline Glyptocephalus cynoglossus (Linnaeus, 1758) & Witch flounder \\
\hline Hemitripterus americanus (Gmelin, 1789) & Sea raven \\
\hline Leucoraja erinacea (Mitchill, 1825) & Little skate \\
\hline Leucoraja ocellata (Mitchill, 1815) & Winter skate \\
\hline Limanda ferruginea (Storer, 1839) & Yellowtail flounder \\
\hline Lophius americanus Valenciennes in Cuvier and Valenciennes, 1837 & Goosefish \\
\hline Melanogrammus aeglefinus (Linnaeus, 1758) & Haddock \\
\hline Merluccius bilinearis (Mitchill, 1814) & Silver hake \\
\hline Myoxocephalus octodecemspinosus (Mitchill, 1814) & Longhorn sculpin \\
\hline Paralichthys dentatus (Linnaeus, 1766) & Summer flounder \\
\hline Paralichthys oblongus (Mitchill, 1815) & Fourspot flounder \\
\hline Pollachius virens (Linnaeus, 1758) & Pollock \\
\hline Pseudopleuronectes americanus (Walbaum, 1792) & Winter flounder \\
\hline Scomber scombrus Linnaeus, 1758 & Atlantic mackerel \\
\hline Scophthalmus aquosus (Mitchill, 1815) & Windowpane \\
\hline Squalus acanthias Linnaeus, 1758 & Spiny dogfish \\
\hline Urophycis chuss (Walbaum, 1792) & Red hake \\
\hline Urophycis tenuis (Mitchill, 1814) & White hake \\
\hline
\end{tabular}

